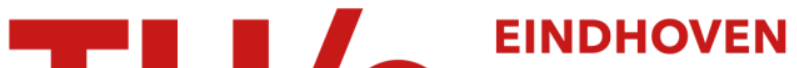 \\ UNIVERSITY OF \\ TECHNOLOGY
}

\section{A static analysis method to determine the availability of kinetic energy from wind turbines}

\section{Citation for published version (APA):}

Rawn, B. G., Gibescu, M., \& Kling, W. L. (2010). A static analysis method to determine the availability of kinetic energy from wind turbines. In Proceedings of the IEEE Power and Energy Society (PES) general meeting, 25-29 July 2010, Minneapolis USA (pp. 1-8). USA.

\section{Document status and date:}

Published: 01/01/2010

\section{Document Version:}

Publisher's PDF, also known as Version of Record (includes final page, issue and volume numbers)

\section{Please check the document version of this publication:}

- A submitted manuscript is the version of the article upon submission and before peer-review. There can be important differences between the submitted version and the official published version of record. People interested in the research are advised to contact the author for the final version of the publication, or visit the $\mathrm{DOI}$ to the publisher's website.

- The final author version and the galley proof are versions of the publication after peer review.

- The final published version features the final layout of the paper including the volume, issue and page numbers.

Link to publication

\section{General rights}

Copyright and moral rights for the publications made accessible in the public portal are retained by the authors and/or other copyright owners and it is a condition of accessing publications that users recognise and abide by the legal requirements associated with these rights.

- Users may download and print one copy of any publication from the public portal for the purpose of private study or research.

- You may not further distribute the material or use it for any profit-making activity or commercial gain

- You may freely distribute the URL identifying the publication in the public portal.

If the publication is distributed under the terms of Article 25fa of the Dutch Copyright Act, indicated by the "Taverne" license above, please follow below link for the End User Agreement:

www.tue.nl/taverne

Take down policy

If you believe that this document breaches copyright please contact us at:

openaccess@tue.nl

providing details and we will investigate your claim. 


\title{
A Static Analysis Method to Determine the Availability of Kinetic Energy from Wind Turbines
}

\author{
Barry G. Rawn, Student Member, IEEE, Madeleine Gibescu, Member, IEEE, Wil L. Kling, Member, IEEE
}

\begin{abstract}
This paper introduces definitions and an analysis method for estimating how much kinetic energy can be made available for inertial response from a wind turbine over a year, and how much energy capture must be sacrificed to do so. The analysis is based on the static characteristics of wind turbines, Weibull distributions of wind speed, and standard definitions of turbulence intensity. A control scheme is presented that extracts an appropriate amount of kinetic energy based on operating point. The tradeoff of wholesale energy revenue for potential kinetic energy revenue is explored. The break-even point is compared with marginal prices for kinetic energy obtained in the literature, and found to be favourable for one example of a full-converter interface wind turbine having a wide speed range.
\end{abstract} kets

Index Terms - wind power generation, inertia, real-time mar-

\section{INTRODUCTION}

\section{A. Background}

Wind turbines and farms are expected to be a signifcant fraction of installed generation capacity in the future, and their current fraction is increasing rapidly. In addition to supplying energy to the power system, wind farms are also required to provide ancillary services such as voltage control, and even the regulation of active power to support the frequency of the power system [6]. One important aspect of power system frequency stability that is not usually classified as an ancillary service is the inertial response of generating units to changes in frequency. In an inertial response to a sudden loss of generation, for example, synchronous generators are physically forced to inject energy into the power grid. That is not the case with converter-interfaced wind turbines [5], [8],[16]. Typical converter controls make the machine appear as a current source in the network with no frequency dependence. Yet, the converter controls can easily be altered to produce any desired dependence on frequency, in particular to cause the injection of rotational kinetic energy into the grid during a frequency event [4], [10], [15]. It has been observed [3],[15] that some of these schemes only temporarily contribute energy

This research is part of the project RegelDuurzaam, which is funded under the SenterNovem program EOS-LT. SenterNovem is an agency of the Dutch Ministry of Economic Affairs

Barry Rawn, Madeleine Gibescu and Wil Kling are with the Department of Electrical Sustainable Energy, Delft University of Technology, 2600 CD Delft, The Netherlands (e-mails:b.g.rawn@tudelft.nl, m.gibescu@tudelft.nl, w.1.kling@tudelft.nl).

Wil Kling is also with the Electrical Power Systems Group, Eindhoven University of Technology, 5612 AZ Eindhoven, The Netherlands (e-mail: w.1.kling@tue.nl). into a frequency drop and mostly affect rate of change of frequency. However, other schemes can be arranged whereby a net contribution of energy is made [4]. This comes at the expense of operating the turbine away from the optimal point, which results in a reduced capture of energy. The contribution possible from a wind turbine can exceed that of a synchronous machine [7]. However, like the active power of a wind farm, it is not always available, and the potential contribution depends on the operating point.

In small power systems found on islands, concerns over frequency stability during contingencies could result on limits to the percentage of installed wind power capacity. It has been proposed to include frequency-related constraints in market dispatch algorithms, and derive a price signal for providing inertial reserve [11]. If a market for kinetic energy were established, this could represent another stream of revenue for wind farm operators. Another scenario is that system operators will mandate the provision of inertial response from all generators. Therefore, it will become important to characterize the capability of inertial response in wind farms in order to exploit the potential of wind farms fully, and to foster further development of wind farms.

\section{B. Contribution}

Inertial response proofs of concept [4],[8] and some analysis of their physical limitations on such schemes appear in the literature. Some of these works investigate operating range and maximum available size [10], [12] or examine how the bound on wind variations constrains safe operation [13]. They do not explore how the longer term variations of the wind resource constrain the availability of kinetic energy. It would be helpful to quantify the magnitude of this energy, how often it can be made available, and what the tradeoff is of providing such a service. The significance of operating point changes must be acknowledged. This paper addresses these issues starting with Section II, which presents an inertial response control scheme that extracts a kinetic energy dependent upon operating point. Section III presents definitions and an analysis method to estimate quantity and availability of kinetic energy reserve, and the sacrifice of energy capture. Section IV presents numerical results, explores the possible tradeoff of wholesale energy revenue for potential kinetic energy revenue is explored, and examines the sensitivity of the results to a site's wind characteristics is presented, based on IEC standard ranges. 


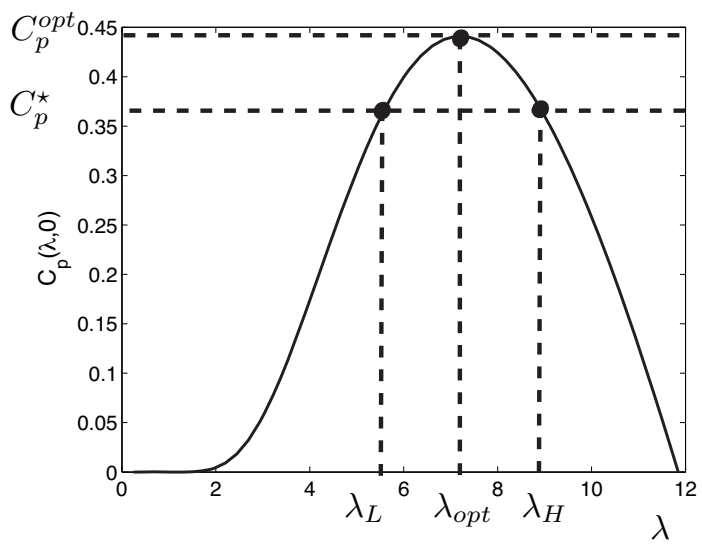

Fig. 1. De-rated operating philosophy, shown on power conversion efficiency curve $C_{p}(\lambda)$. Operation occurs not around optimal tip-speed ratio $\lambda_{p p t}$, but around $\lambda_{H}$ at a de-rated efficiency $C_{p}^{\star}$. A reserve of kinetic energy is made availble between $\lambda_{H}$ and $\lambda_{L}$.

\section{Modeling AND Assumptions}

\section{A. Reserve Capability and De-rating}

A wind turbine converts the power in flowing mass of air to mechanical power with a variable efficiency using its bladed rotor. The aerodynamic characteristics of the blades result in an efficiency that varies with tip-speed ratio $\lambda$

$$
\lambda=\frac{R \omega}{v}
$$

where the windspeed is $v$, and the speed of the blade tip is determined by the turbine radius $R$ and rotational speed $\omega$. The power conversion efficiency $C_{p}(\lambda)$, depicted in Fig. 1 is nonlinear, with a peak value $C_{p}^{o p t}$ at an optimal tip-speed ratio $\lambda_{o p t}$. The wind turbine power is given by

$$
P(\bar{v}, \lambda)=\frac{1}{2} \pi \rho \pi R^{2} C_{p}(\lambda) v^{3}
$$

A de-rated efficiency occurs for $\lambda \neq \lambda^{o p t}$, and a chosen derating can be obtained over a wider speed range. For example, in Fig. 1, a derated efficiency of $C_{p}{ }^{\star}$ has been chosen. If, for a given wind speed, the tip-speed ratio $\lambda_{o p t}$ produces a power $P_{o p t}$, then operating at either $\lambda_{L}$ or $\lambda_{H}$ would yield a power $P_{\star}<P_{\text {opt }}$. For tip speed ratios in the interval $\left[\lambda^{l}-\lambda^{h}\right]$, the efficiency of conversion is at least $C_{p}{ }^{\star}$ or greater. A de-rating $\alpha$ in percent is defined as follows:

$$
\alpha=\left(1-\frac{C_{p}^{\star}}{C_{p}{ }^{o p t}}\right) * 100
$$

For a given constant wind speed $v$ and de-rating $\alpha$, the rotational speed of the wind turbine can be reduced from a speed $\omega_{H}$ to as low a speed as $\omega_{L}$ implied by (1):

$$
\left[\omega_{L}, \omega_{H}\right]=\frac{v}{R}\left[\lambda_{L}, \lambda_{H}\right]
$$

The effect of such a reduction is depicted in Fig. 2. The difference in kinetic energy can be extracted to make a change in power $\Delta P$ for a duration $\tau$. De-rating to the non-optimal efficiency $C_{p}^{\star}$ thus makes a reserve of kinetic energy available.

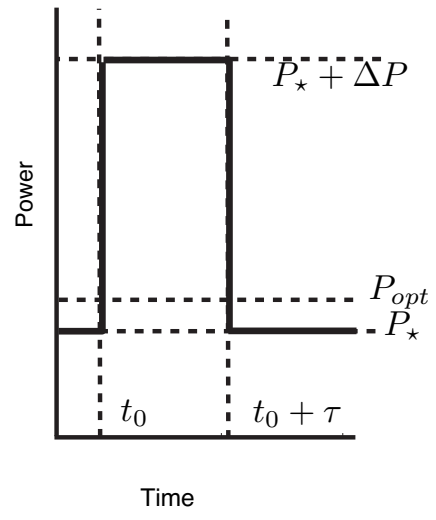

(a) Power

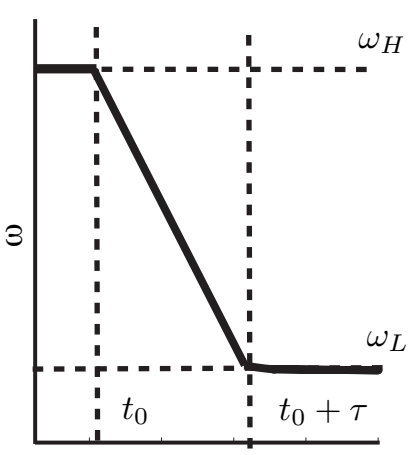

Time

(b) Rotational speed
Fig. 2. Illustration of kinetic energy reserve due to de-rating. Reserve is tapped to provide an power pulse $\Delta P$ over duration $\tau$ without dipping below level $P_{\star}$.

The quantity of energy available will depend on the operating wind speed and the turbine's rotor inerta $J$, as follows

$$
\Delta E_{K}\left(\bar{v}, \lambda_{H}\right)=\frac{1}{2} J\left(\frac{\bar{v}}{R}\right)^{2}\left(\lambda_{H}^{2}-\lambda_{L}^{2}\right)
$$

where $\lambda_{L}$ is the value of $\lambda$ such that $C_{p}\left(\lambda_{L}\right)=C_{p}\left(\lambda_{H}\right)$, as in Fig. 1. A small reserve of power is made available through derating. Power reserve can also be obtained be altering the pitch of the wind turbine blades. Neither capability is of interest for this work.

\section{B. Generator Torque Control and Operating Ranges}

To maximize energy capture, turbine controls are usually set to cause changes in $\omega$ so as to maintain $\lambda$ at $\lambda_{\text {opt }}$ when changes in wind speed occur [14]. This is possible only in the variable speed range of a wind turbine, and can achieved by setting a generator torque that has appropriate intersections with the wind-dependent aerodynamic torque curves. This is achieved by setting the following torque with $\lambda_{\star}=\lambda_{o p t}$ :

$$
T_{\text {gen }}=\underbrace{\frac{1}{2} \pi \rho C_{p}\left(\lambda_{\star}\right) \frac{R^{5}}{\lambda^{3}}}_{k_{\text {load }}\left(\lambda_{\star}\right)} \omega^{2}
$$

Such a torque is depicted in Fig. 3 as a thick solid line. The aerodynamic torque is derived by dividing (2) by $\omega$ and is depicted using thin solid lines for a number of threshold wind speeds. There are a number of different operating modes of a wind turbine that are partly enforced by generator torque, and by blade pitch [1]. These modes occur at the speeds $v_{1}-v_{6}$, which are described in Table $I$ and shown in Fig. 3 for a particular model of turbine.

The limits on variable speed range are imposed by the power electronic frequency converter at low speed [1], and the maximum allowable speed of the wind turbine at high speed [9]. The optimal generator torque is not permitted to intersect these limiting speeds discontinuously. Instead it is set to ramp towards these operational endpoints starting above $\omega^{\text {lower }}$ and below $\omega^{\text {upper }}$ [14]. This reduces fluctations in power as the 


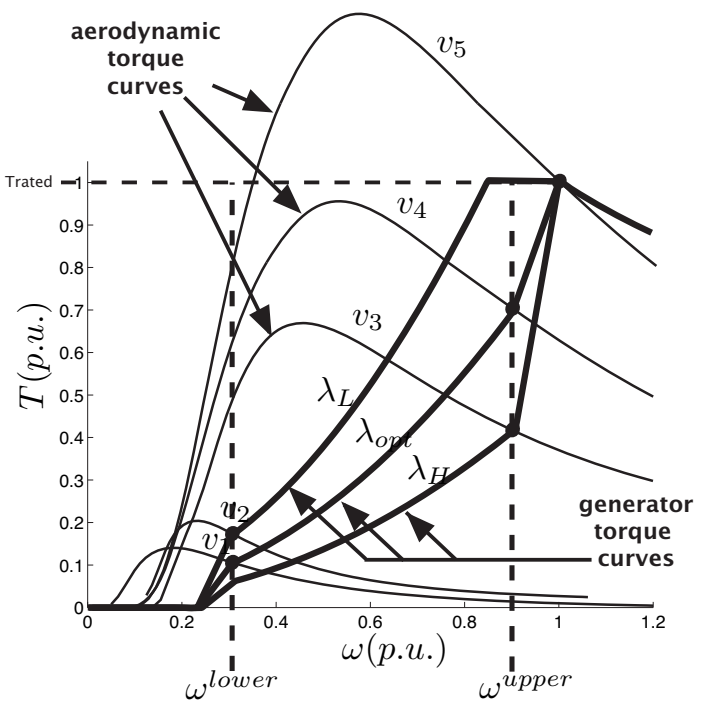

Fig. 3. De-rated load curves for $\lambda_{o p t}$ and $\lambda$ corresponding to $\alpha=2 \%$ intersecting with aerodynamic torque curves for threshold wind speeds of Table 1.

turbine transitions between zero and full rated power, and also eases the task of the pitch control at high speeds, which activates to limit the rotational speed of the wind turbine by spilling aerodynamic power [9].

For an optimal generator torque, the wind speeds at which all of these transitions occur are marked in Fig. 3 and listed in Table. I. These wind speeds denote the different operating modes of the windturbine. It is also possible to set the generator torque curve to produce intersections that preserve a different tip-speed ratio $\lambda_{\star}$ (for example, $\lambda_{H}$ or $\lambda_{L}$ instead of $\left.\lambda_{o p t}\right)$. This is achieved by replacing the parameter $\lambda_{\text {opt }}$ with $\lambda_{\star}$ in the gain $k_{\text {load }}(\lambda)$ in (6). Wind speeds corresponding to operation at the tip-speed ratios $\lambda_{L}$ and $\lambda_{H}$ are also marked in the figure and listed in Table. I.

\begin{tabular}{|c|c|c|}
\hline Wind Speed Threshold & Value $(\mathrm{m} / \mathrm{s})$ & \\
\hline$v_{1}$ & cut-in, optimal & 2.5 \\
\hline$v_{2}$ & cut-in, reserve depleted $\left(\lambda_{L}\right)$ & 3.9 \\
\hline$v_{3}$ & transition zone, de-rated $\left(\lambda_{R}\right)$ & 6.9 \\
\hline$v_{4}$ & transition zone, optimal $\left(\lambda_{o p t}\right)$ & 11 \\
\hline$v_{5}$ & rated speed and power reached & 13.5 \\
\hline$v_{6}$ & cut-out wind speed reached & 31 \\
\hline
\end{tabular}

TABLE I

TABLE OF WIND SPEED THRESHOLDS DEMARCATING DIFFERENT OPERATING MODES, ENERCON E-70 WIND TURBINE.

\section{Kinetic Energy Extraction}

Most works in the literature that address exploitation of wind turbine kinetic energy consider its application to inertial response. There are a variety of controllers that may be applied to produce an injection of power that reduces the rotational speed of the turbine [4],[8], [10],[7]. These controllers must be designed not to cause violations of rotational speed limits or converter current limits. This paper aims only to introduce basic concepts about availability and produce a basic evaluation of the available energy, and so some simplifying assumptions

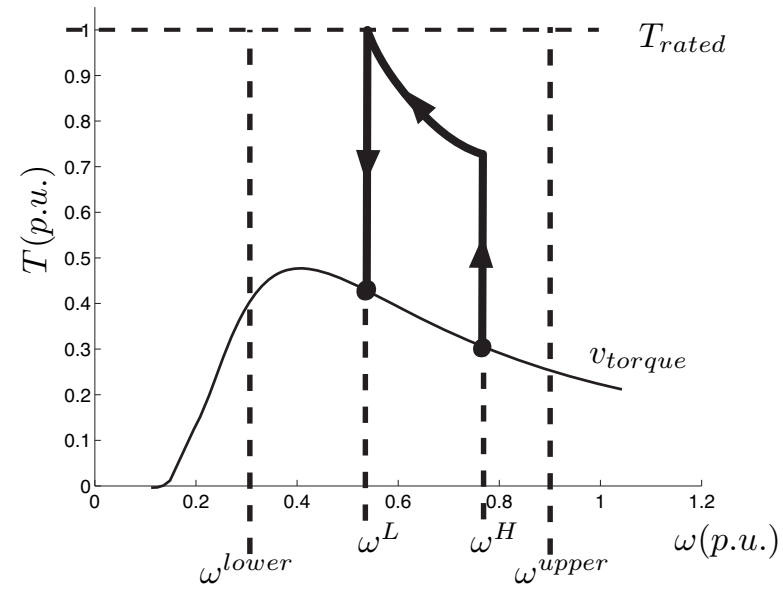

Fig. 4. Transient in torque-speed plane for constant power pulse and limiting value of wind speed vtorque.

are employed. It is assumed that during the short period that kinetic energy is provided, the wind speed is constant. A control for extracting kinetic energy as a constant power pulse of limited duration [10], [7] is selected because it is simplest. An enhancement of such methods is presented here to allow an analysis over all operating points. The control is a $\Delta T$ that is added to the generator torque curve:

$$
\Delta T(\omega, t)=\left\{\begin{array}{cc}
\frac{\Delta P\left(t_{0}\right)}{\omega}, & t_{0}<t<t_{0}+\tau \\
T_{o p}, & t>t_{0}+\tau
\end{array}\right.
$$

where the quantity $\Delta P$ is the constant power pulse used to deliver the available energy reserve, as shown in Fig. 2, the time $\tau$ is a chosen duration, $t_{0}$ is the time of activation and the constant quantity $T_{o p}$

$$
T_{o p}\left(t_{0}\right)=k_{\text {load }}\left(\lambda_{H}\right)\left(\left(\frac{\lambda_{H}}{\lambda_{L}}\right)^{3}-1\right) \omega\left(t_{0}\right)^{2}
$$

is a torque added to the generator load torque to maintain the new operating point at $\omega_{L}$.

The $\Delta P\left(t_{0}\right)$ chosen in this control strategy would have to be based instead on rotational speed $\omega$, the only measurement reliably available. By assuming that the current speed is indeed tracking the desired $\lambda_{H}$, the wind speed would be estimated as

$$
\hat{v}_{w}=\frac{R}{\lambda_{H}} \omega
$$

and the estimate of available energy would be obtained by substituting into (5):

$$
\Delta \hat{E}_{K}\left(t_{0}\right)=\frac{1}{2} J \omega\left(t_{0}\right)^{2}\left(1-\left(\frac{\lambda_{L}}{\lambda_{H}}\right)^{2}\right)
$$

This reserve of kinetic energy will be depleted for any $\Delta P$ that exceeds maximum power available. Any combination of $\Delta P$ and $\tau$ will achieve this according to the formula:

$$
\Delta P\left(t_{0}\right)=\frac{\Delta \hat{E}_{K}\left(t_{0}\right)}{\tau}
$$

Typically kinetic energy is of value when delivered quickly during a frequency drop; a reasonable amount for $\tau$ might be $1-5$ seconds. 


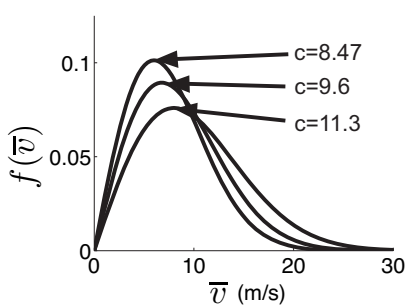

(a) $c$ parameter of IEC I, II, and III. (b) $k$ parameter over typical range, for $k=2$

Fig. 5. Effect on probability distribution function $f(\bar{v})$ of varying shape $k$ and scale $c$ parameters over ranges specified by the IEC.

The resulting type of transient is shown on the torquespeed plane in Fig. 4. The limits on such a response due to speed limits and torque limits will be evaluated in the Analysis section.

\section{Wind Resource}

Ten minute averages of wind speed measurements are frequently used to determine the statistics of a wind turbine site's resource. Such statistics are used to assess the yearly production of wind farms. The probability distribution of wind speeds is widely recognized to be well-fit by a Weibull distribution

$$
f(\bar{v})=\frac{k}{c}\left(\frac{\bar{v}}{c}\right)^{k-1} e^{-\left(\frac{\bar{v}}{c}\right)^{k}}
$$

where $\bar{v}$ is the ten minute average value, "c" is called a scale parameter and "k" is called a shape parameter. Fig. 5 shows a set of probability distribution functions that result from typical values of these parameters [2],[1]. Substantial fluctuation in wind speed can occur within a 10 minute period, with periods of 10 minutes to 1 second. These fluctuations cause significant changes in wind turbine operating point. The distribution of wind speeds around a 10 minute average value can be viewed as Gaussian, and therefore characterized by a standard deviation $\sigma$ dependent on the mean $\bar{v}$ over a 10 minute interval. The turbulence intensity T.I. is the ratio of these two quantities.

$$
T . I=\frac{\sigma}{\bar{v}}
$$

The turbulence intensity varies in general with the mean value $\bar{v}$. In calculations of energy yield, the effect of turbulence is usually neglected, possibly due to cancelation [1]. However, in this paper, normally distributed turbulent variations will be accounted for along with the Weibull distribution to understand variations in wind turbine operating point.

\section{Analysis Method}

As is well known in the field, the energy capture of a wind turbine can be estimated using the probability distribution of wind speeds. The distribution $f(\bar{v})$ is given by (12) and the power at a given wind speed can be obtained from (2) by assuming $\lambda=\lambda_{\star}$, where $\lambda_{\star}$ corresponds to a desired $\alpha$. The yearly capture in $M W h$ of a wind turbine eligible for sale on

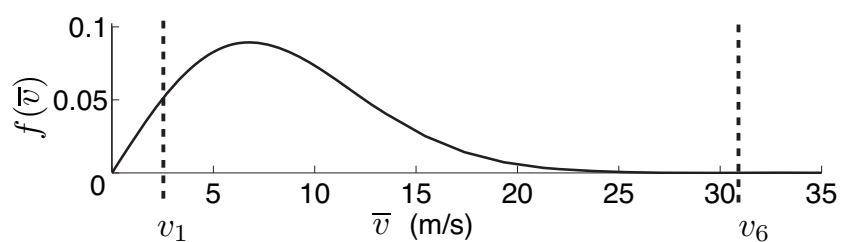

(a) Probability density $f(\bar{v})$ of 10 minute average wind speed $\bar{v}$



(b) Power curve $P\left(\bar{v}, \lambda_{\star}\right)$

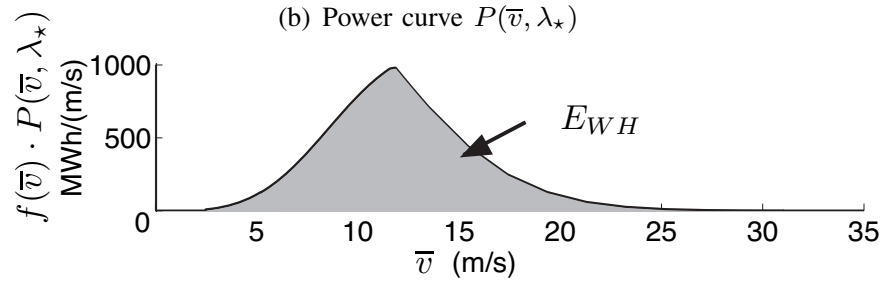

(c) Wholesale energy capture density.

Fig. 6. Illustration of computation of energy capture for wholesale market. Turbine produces between wind speeds $\bar{v}_{1}$ and $\bar{v}_{6}$ (dashed lines).

the wholesale energy market is referred in this paper to as a quantity $E_{W H}$ and given by integrating the product:

$$
E_{W H}=\frac{\text { seconds/year }}{J / M W h} \int_{v_{2}}^{v_{6}} f(\bar{v}) P\left(\bar{v}, \lambda_{o p t}\right) d v
$$

where $v_{1}$ and $v_{6}$ are the cut-in and cut-out speeds given in Table I. This paper uses a similar approach to analyze the provision of kinetic energy and its consequences for energy capture. It is illustrated in Fig. 7. A curve $E_{K R}\left(\bar{v}, \lambda_{\star}\right)$ giving the dependence of kinetic energy reserve on wind speed (Fig. 7(b) is derived in analogy to $P\left(\bar{v}, \lambda_{\star}\right)$, so that a cummulative kinetic energy reserve $E_{C K R}$ (area in Fig. 7(c)) available over a year can be determined by integrating the product:

$$
E_{C K R}=N_{i n t} \int_{v_{L}}^{v_{H}} f(\bar{v}) E_{K R}\left(\bar{v}, \lambda_{\star}\right) d v
$$

where $N_{\text {int }}$ is the number of 10 minute intervals in a year, $v_{L}$ and $v_{H}$ denote the lowest and highest wind speeds for which a kinetic energy reserve can be reliably made available, and $E_{K R}$ is the magnitude of that reserve. The calculation of the speeds and magnitude is detailed in sections III.A and III.B. When de-rating is applied over the range $\left[v_{L}, v_{H}\right]$, a quantity of energy capture $\Delta E_{W H}$ is sacrificed:

$\Delta E_{W H}=\frac{\text { seconds/year }}{J / M W h}\left(1-\frac{C_{p}^{\star}}{C_{p}^{o p t}}\right) \int_{v_{L}}^{v_{H}} f(\bar{v}) P\left(\bar{v}, \lambda_{\star}\right) d v$

This quantity can be computed to evaluate the economic tradeoff of providing reserve. 




(a) Probability density $f(\bar{v})$ of 10 minute average wind speed $\bar{v}$

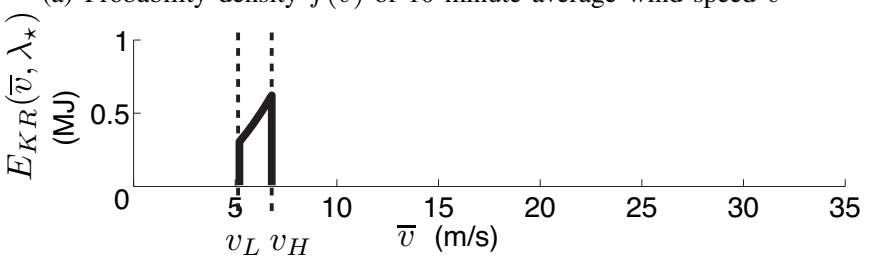

(b) Minimum available kinetic energy $E_{K R}\left(\lambda_{\star}, \bar{v}\right)$

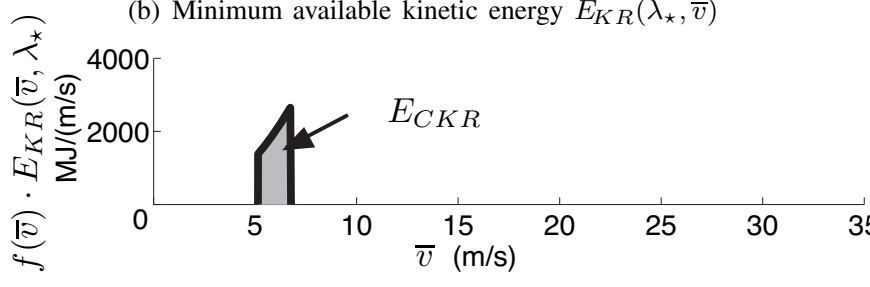

(c) Kinetic energy reserve density.

Fig. 7. Illustration of analysis method. Within the range of wind speeds $\left[v_{L}, v_{H}\right]$ (dashed lines) whose computation is outlined by the paper, kinetic energy reserve can be made available by sacrificing energy capture by derating. $\alpha=2 \% c=9.6, k=2$

\section{A. Calculation of Wind Speed Range $\left[v_{L}, v_{H}\right]$ Corresponding to Kinetic Energy Availability}

The wind turbine dynamics due to the rotor's inertia and spatial filtering of windspeed will be neglected. Including such effects requires a more sophisticated analysis, additional assumptions, and a proper model of wind speed spectral content. It is be assumed that the speeds $\omega_{L}$ and $\omega_{H}$ can be algebraically associated with wind speed inputs through the relation (1). Thus, the limits $\omega_{\text {lower }}$ and $\omega_{\text {upper }}$ translate directly into a range of wind speeds outside of which kinetic energy can not be extracted. The maximum limit on generator torque can in some cases further resrict the viable range of wind speeds. Also, the actual range of windspeeds used in the analysis must be adjusted for turbulence.

1) Torque Constraint: A constant power curve in the torque speed plane implies an increasing torque as speed decreases, as shown in Fig. 4, and this means that the maximum torque of the transient will be reached at the speed $\omega_{L}$. The condition that generator torque reaches the rated value $T_{\text {rated }}$ at $\omega_{L}$ corresponds to a worst case wind speed $\bar{v}_{\text {torque }}$. This worst case speed depends on the de-rating $\alpha$, which determines $\omega_{L}$, and the discharge duration $\tau$, which determines the height of $\Delta T$ through (11) and (5). An expression determining $\bar{v}_{\text {torque }}$ can be found as follows. The total generator torque during a transient is obtained by adding (6) and (7) at $t=t_{0}+$ $\tau$. Substituting in (1) to eliminate $\omega$, the critical condition depicted in Fig.4 is:

$$
\begin{aligned}
T_{\text {rated }} \geq k_{\text {load }}\left(\lambda_{H}\right) & \left(\frac{\lambda_{L}}{R}\right)^{2} v_{\text {torque }}^{2} \\
& +\Delta P\left(\frac{R}{\lambda_{L} v_{\text {torque }}}\right) \cdot \frac{R}{v_{\text {torque }} \lambda_{L}}
\end{aligned}
$$

where $\omega$ has been set to $\omega_{L}$ and expressed in terms of wind speed and tip-speed ratio $\lambda_{L}$ via (1). Substituting (11),(10), and (9), and setting $\hat{v}_{w}=v_{\text {torque }}$, one obtains this equation for $v_{\text {torque }}$ :

$$
\begin{aligned}
T_{\text {rated }} \geq k_{\text {load }}(\lambda) & \left(\frac{\lambda_{L}}{R}\right)^{2} v_{\text {torque }}^{2} \\
+ & \frac{J}{2 \tau}\left(1-\left(\frac{\lambda_{L}}{\lambda_{R}}\right)^{2}\right) \frac{\lambda_{H}^{2}}{R \lambda_{L}} v_{\text {torque }}
\end{aligned}
$$

Whether this torque-limit induced limit on wind speed is more restrictive than that caused by upper rotor speed depends 35 on the characteristic $C_{p}(\lambda)$ of the turbine, the amount of derating $\alpha$, and the desired duration of discharge $\tau$. For smaller de-ratings and longer durations of discharge, (e.g. for the model studied, $2 \%$ or less and longer than 3 seconds), the wind speed $v_{\text {torque }}$ is lower than the wind speed $v_{3}$ associated with upper rotational speed limit $\omega^{\text {upper }}$. In other cases, the availability is further reduced.

2) Accounting for Turbulence: It is important to account for how turbulent variations in wind speed will affect the occurence of different operating points. Within a ten minute interval the wind speed, and hence the operating rotational speed, will vary significantly. Two standard deviations are taken as the likely range of wind variations around the interval's mean value $\bar{v}$, representing a probability of $95 \%$. An IEC standard gives guidelines for turbulence intensity [2] and through (13) the magnitude of the standard deviation $\sigma(\vec{v})$. The range of possible wind speeds can be computed as:

$$
\bar{v} \pm 2 \sigma(\bar{v})=\bar{v}\left(1 \pm 2 I_{15} \frac{a+\frac{15}{\bar{v}}}{1+a}\right)
$$

where $I_{15}$ has high and low values of 0.12 and 0.16 , and $a$ has values between 2 and 3 [2], corresponding to the IEC turbulence classes C-A respectively.

The values $v_{L}$ and $v_{H}$ to be used in this analysis are obtained by equating (19) to critical values of wind speed and solving:

$$
\begin{aligned}
v_{L} & =\frac{v_{2}+2 \frac{I_{15}}{1+a}}{1-2 \frac{I_{15}}{1+a} a} \\
v_{H} & =\frac{\min \left(v_{3}, v_{\text {torque }}\right)-2 \frac{I_{15}}{1+a}}{1+2 \frac{I_{15}}{1+a} a}
\end{aligned}
$$

where $v_{2}$ and $v_{3}$ are given in Table I and $v_{\text {torque }}$ is implicity defined in (18). In this work it is assumed that $\tau$ and $\alpha$ have been chosen such that $v_{\text {torque }}>v_{3}$.

\section{B. Probable Quantity of Kinetic Energy}

It must be assumed that during a 10 minute interval, any wind variation within 2 standard deviations $\sigma$ can occur. 


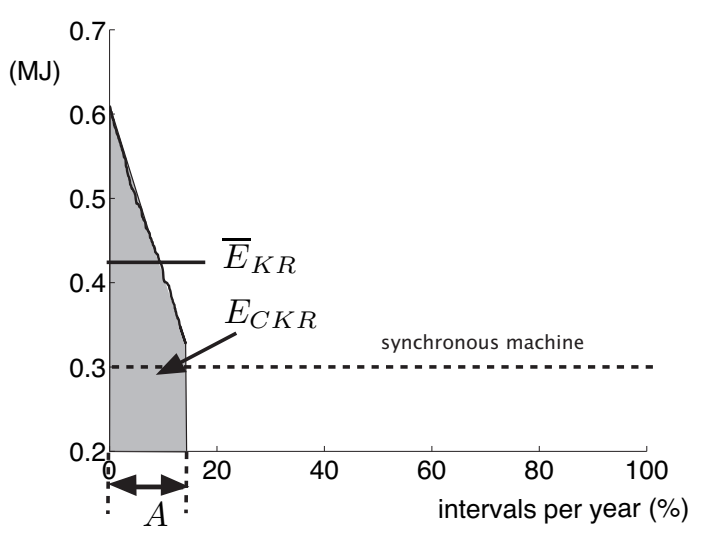

Fig. 8. Duration curve of kinetic energy reserves $E_{K R}\left(\bar{v}, \lambda_{\star}\right)$ over a year of ten-minute intervals, for a wind turbine (solid) and synchronous generato (dashed). The availability $A$, mean reserve $\bar{E}_{K R}$, and cummulative kinetic energy reserve $E_{C K R}$ (shaded area), are marked on the figure

Thereis thus a range of possible kinetic energy reserve. It is conservative to use the lower bound in the calculation of kinetic energy reserve $E_{K R}$, so that it can then be interpreted as a quantity that can be guaranteed over the 10 minute interval. Thus,

$$
\left.E_{K R}\left(\bar{v}, \lambda_{\star}\right)\right)=\frac{1}{2} J\left(\frac{\bar{v}-2 \sigma(\bar{v})}{R}\right)^{2}\left(\lambda_{\star}^{2}-\lambda_{L}^{2}\right)
$$

where $\bar{v}$ is ten-minute mean, $\sigma(\bar{v})$ is the standard deviation for that mean value, $J$ is the turbine inertia, and $\lambda_{L}$ is such that $C_{p}\left(\lambda_{\star}\right)=C_{p}\left(\lambda_{L}\right)$.

\section{Results}

Computations are based on a division of the year into 10 minute intervals, where the intervals have mean wind speeds $\bar{v}$ that have a Weibull distribution corresponding to an IEC site of class $I I_{B}$ (values $k=2, c=9.6$, and T.I. $=0.14$ ) The sensitivity of the results to $k, c$, and T.I is examined at the end of the section. For all of those intervals having a windspeed that lies within $\left[v_{L}, v_{H}\right]$, the kinetic energy reserve $E_{K R}\left(\bar{v}, \lambda_{\star}\right)$ can be computed. In Fig. 8, the values have been computed for a de-rating $\alpha=2 \%$ and sorted from highest to lowest, forming a duration curve for kinetic energy reserve. This curve can be used to make several observations and definitions. The percentage of intervals when kinetic energy is available is denoted by $A$. The mean value of reserve available is denoted as $\bar{E}_{K R}$. The cumulative quantity of kinetic energy reserve $E_{C K R}$ defined earlier as (15) corresponds to the shaded area. This area clearly depends on the quantities $A$ and $\bar{E}_{K R}$.

For comparison, a horizontal line in Fig. 8 shows the energy that would be available from a synchronous generator having the same physical inertia as a wind turbine. The quantity released in a relatively large frequency deviation of $1 \%$ has been chosen for comparison. Because of its ability to run asynchronously, the wind turbine is capable of delivering twice this amount (and as much as five times at higher de-ratings, see Fig. 9). However, during some ten-minute intervals of the year, providing such an amount may be either impossible or



Fig. 9. Dependence on de-rating $\alpha$ of mean kinetic energy reserve $\bar{E}_{K E}$ and its availability $A$. Increasing quantity of reserve is countered by a decreased number of available intervals.

uncertain. The shaded area $E_{C K R}$ would be proportional to profit in a kinetic energy reserve market. It is evident that a wind turbine would have to have a larger inertia to have the same potential for profit. Also, for the example shown, kinetic energy reserve would be unavailable $85 \%$ of the time.

\section{A. Dependence of Kinetic Energy Availability and Quantity on De-rating}

While adjusting the de-rating of the generator torque makes a greater reserve of energy possible, such a reserve is available for a smaller fraction of time. This can be observed from in Fig 9. For this case of a full-converter interfaced wind turbine with a wide speed range, it appears that the average kinetic energy offered could range from 3 MJ, offered $2 \%$ of the time, to $0.1 \mathrm{MJ}$, offered $20 \%$ of the time. It must be mentioned that the model of turbine studied has a wide rotational speed range and thus other models would have both a lower availability. The conflicting trends of Fig 9 suggest that the cumulative amount of kinetic energy available from the turbine is maximized by some particular value of de-rating. In Fig 10, the cumulative quantity of reserve available over the year $E_{C K R}$ is plotted. This quantity is maximized for this example around $\alpha=2 \%$. The quantity that could be expected from a synchronous machine with equal inertia, during a $1 \%$ frequency drop, is also plotted as a dashed line. The available reserve over a long period from the wind turbine is less than that expected from a synchronous machine of the same inertia, even though for a given interval it may be able to supply much more kinetic energy than a synchronous machine.

\section{B. Dependence of Energy Capture on De-rating}

The penalty of offering kinetic energy is reduced energy capture. Ideally, as assumed by (16), de-rating would not be used except during ten-minute intervals when mean wind speed was expected to fall in the interval $\left[v_{L}, v_{H}\right]$. In Fig 11, the quantity of energy sacrificed to provide kinetic energy reserve is plotted. Due to the low energy density in the range $\left[v_{L}, v_{H}\right]$ and limited availability, the reduction in energy capture is small. For example, at a de-rating of $2 \%$, the change $\Delta E_{W H}$ in energy capture is only $0.08 \%$. 


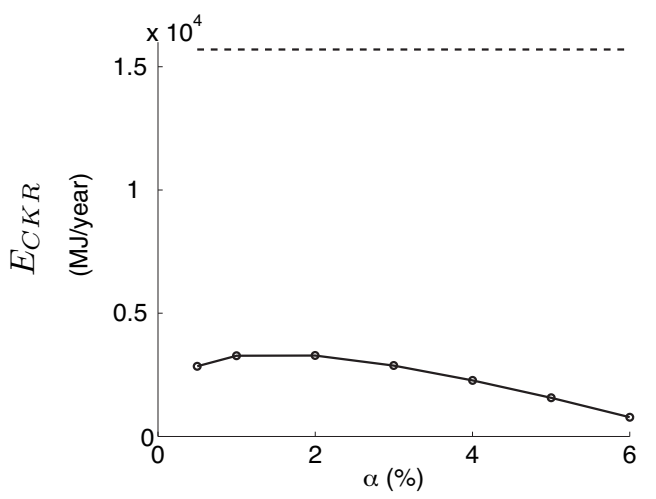

Fig. 10. Yearly $E_{C K R}$, as function of de-rating $\alpha$ for wind turbine (solid) and synchronous machine of equal inertia (dashed). A maximum occurs close to $\alpha=2 \%$ for the wind turbine chosen.

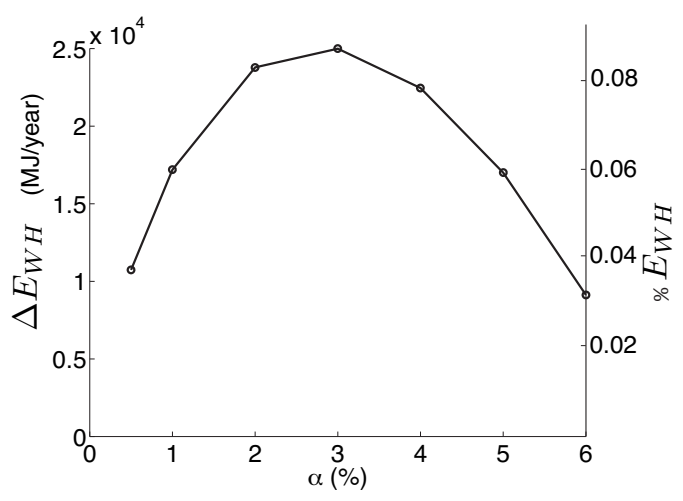

Fig. 11. Sacrifice of energy capture traded for kinetic energy reserve, ove year, as a function of de-rating. Total capture is $29.1 \cdot 10^{6} \mathrm{MJ}$ (8090 MWh)

\section{Break-even Analysis}

It may be that in systems with a high amount of wind power, the provision of kinetic energy from wind farms would be mandated by grid code. In that case, the economic burden of doing so is of interest, and this can be inferred from Fig. 11. In the event that some compensation is provided for such a service, it also becomes of interest to know what price would make the service viable or even profitable for a wind farm operator.

Let the price offered for a unit of energy on the wholesale market be $p_{W H}$, and that offered for kinetic energy reserve be $p_{K R}$. If the quantities of energy sacrificed and delivered into these two markets over the course of year are $\Delta E_{W H}$ and $E_{C K R}$ respectively, then the condition of breaking even is

$$
p_{K R} E_{C K R}-p_{W H} \Delta E_{W H}=0
$$

and a break-even ratio $r_{B E}$ can be identified:

$$
r_{B E}=\frac{p_{K R}}{p_{W H}}=\frac{\Delta E_{W H}}{E_{C K R}}
$$

In Fig $12, r_{B E}$ is plotted. It appears that that short-term kinetic energy reserve would have to be valued significantly higher than wholesale energy if the offering of kinetic energy reserve were to be economically neutral. If the de-rating $\alpha$ is chosen in the range $0.5 \%-3 \%$ so as to yield a useful availability, then the break-even ratio $r_{B E}$ ranges from about



Fig. 12. Break-even price ratio $r_{B E}$ of the kinetic energy reserve price to the wholesale price, as a function of de-rating.



(a) Availability (as percentage of total \# 10 minute intervals)

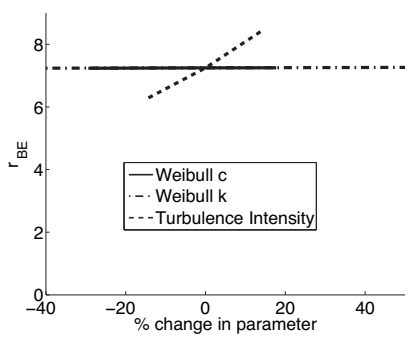

(b) Break-even price ratio $r_{B E}$
Fig. 13. Sensitivity to site wind resource parameters for de-rating of $2 \%$; plot ranges over IEC standard classes IEC I-IV, turbulence A-C, k 1.2-3.

4 to 8 . A marginal price for kinetic energy has been inferred in one literature study of a power system dispatch model and its security constraints [11]. The breakeven ratio $r_{B E}$ can be compared with the ratio of prices observed in that work. For illustration, $\alpha=2 \%$ will be chosen, with a break-even ratio of 7. Assuming a spot price of 30 euro/MWh as in [11], this would translate to a value of 0.06 euro/MJ for reserve kinetic energy. This outcome is promising, as the marginal price for kinetic energy inferred in [11] was at least this amount, and sometimes as much as 4-5 times as much.

\section{Sensitivity Analysis}

The sensitivity of the preceeding results to the characteristics of the wind resource has been studied by taking IEC classes as a reasonable range of possible values. The "c" and " $k$ " parameters vary over the IEC classes I-III as indicated in Fig. 5, and three turbulence intensity classes A-C are identified by the IEC [2]. The sensitivity of the availability $A$ and the break-even price ratio $r_{B E}$, are shown in the so-called "spider plots" of Fig. 13(a) and 13(b). For the model wind turbine studied, availability varied as much as $\pm 50 \%$ with site parameters, but did not reduce to zero for any of the IEC classes. Higher availability corresponded to site parameters corresponding to low mean wind speed, high shape factors, and low turbulence intensity. Break-even ratio was relatively insensitive to site parameters, except for turbulence intensity. This may be due to the tradeoff between $\mathrm{A}$ and $\bar{E}_{k}$. 


\section{COnCLusions}

The kinetic energy reserve available from wind turbines using a de-rating philosophy was studied. De-rating increases the size of the reserve but decreases its availability, and there is thus an optimal de-rating from the perspective of yearly cummulative kinetic energy reserve. For the wind turbine chosen and an IEC $I I_{B}$ wind resource, the kinetic energy reserve made available was maximized by a de-rating of about $2 \%$. For this de-rating, a reserve of energy $0.3 \mathrm{MJ}$ could be made available $15 \%$ of the time. A synchronous machine offers a similar quantity of reserve during a major frequency drop, but does so continuously. The yearly quantity of kinetic energy made available for a de-rating of $2 \%$ was $3200 \mathrm{MJ}$, which is about one-fifth the quantity that would be available from a synchronous machine over the same period. To obtain this quantity, about $0.08 \%$ of total yearly capture would be sacrificed from sales on the wholesale market. It was found that the market value of kinetic energy reserve per unit of energy would have to be seven times that of wholesale energy in order for economic break-even.

This analysis has been based on probability distributions, which offer easy computation of cumulative results based on analytical expressions, but cannot describe the consequences of time variations. Also, the sensitivity of the results to wind turbine model should be investigated. Approximations were necessary that give a pessimistic estimate of the kinetic energy reserve. In order to more accurately assess the availability of kinetic energy from wind turbines, an analysis method should account for the spectral content of wind speed and wind turbine dynamics in the minute to second range time scale. In addition, allowing shorter market intervals might allow a better exploitation of the kinetic energy reserve.

\section{REFERENCES}

[1] T. Burton, D. Sharpe, N. Jenkins, and E. Bossanyi. Wind Energy Handbook. Wiley, 2001.

[2] International Electrotechnical Commission. IEC 61400-1, Wind Turbines - Part 1: Design Requirements. Wiley, 2001.

[3] J. Conroy and R. Watson. Frequency response capability of full converter wind turbine generators in comparison to conventional generation. IEEE Transactions on Power Systems, 23(2), May 2008.

[4] J. Ekanayake and N. Jenkins. Comparison of the response of doubly fed and fixed-speed induction generator wind turbines to changes in network frequency. IEEE Transactions on Energy Conversion, 19(4):800-802, 2004.

[5] M. O'Malley G. Lalor, A. Mullane. Frequency control and wind turbine technologies. IEEE Transactions on Power Systems, 20(40):1905-1913, November 2005.

[6] C. Jauch, J. Matevosyan, T. Ackermann, and S. Bolik. International comparison of requirements for connection of wind turbines to power systems. Wind Energy, 8:295-306, 2005.

[7] P.K. Keung, P. Lei, H. Banakar, and B.T. Ooi. Kinetic energy of windturbine generators for system frequency support. IEEE Transactions on Power Systems, 24(1):279-287, 2009.

[8] J. Morren, S. W. H de Haan, W. L. Kling, and J.A Ferreira. Wind turbines emulating inertia and supporting primary frequency control IEEE Transactions on Power Systems, 21(1):433-434, Februrary 2006.

[9] E. Muljadi and C.P Butterfield. Pitch-controlled variable-speed wind turbine generation. IEEE Transactions on Industry Applications, 37(1):240-246, Jan/Feb 2001.

[10] N.Ullah, T. Thiringer, and D. Karlsson. Temporary primary frequency control support by variable speed wind turbines. IEEE Transactions on Power Systems, 23(2):601-612, May 2008.
[11] M. O'Malley R. Doherty, G. Lalor. Frequency control in competitive market dispatch. IEEE Transactions on Power Systems, 20(3):15881596, August 2005.

[12] B. Rawn and P.W. Lehn. Wind rotor inertia and variable efficiency: fundamental limits on their exploitation for inertial response and power system damping. In European Wind Energy Conference 2008, March 31-April 32008.

[13] B. Rawn and P.W. Lehn. A method for assessing stability of wind turbines providing grid frequency stabilization. In Nordic Wind Power Conference 2009, Sept 10-11 2009.

[14] J. G. Slootweg, H. Polinder, W. L. Kling, and J.A Ferreira. Representing wind turbine electrical generating systems in fundamental frequency simulation. IEEE Transactions on Energy Conversion, 18(4):516-524, December 2003.

[15] G. Tarnowski, P. Kjaer, P. Sørensen, and J. Østergard. Study on variable speed wind turbines capability for frequency response. In Proceedings of the 2009 European Wind Energy Conference, 2009.

[16] E. Vittal, J.D McCalley, V. Ajarapu, and T. Harbour. Wind penetration limited by thermal constraints and frequency stability. Power Symposium, 2007. NAPS '07. 39th North American, pages 353-359, 2007.

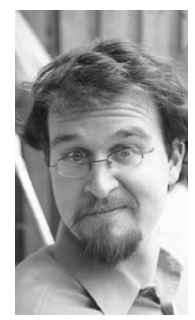

Barry G. Rawn (S03) received the $\mathrm{PhD}$ degree in electrical engineering from the Department of Electrical \& Computer Engineering at the University of Toronto in March 2010, where he received the BASc and MASc degrees in Engineering Science and Electrical Engineering respectively from the University of Toronto in 2002 and 2004. He is currently a postdoctoral researcher in the Department of Electrical Sustainable Energy at the Delft University of Technology, The Netherlands.

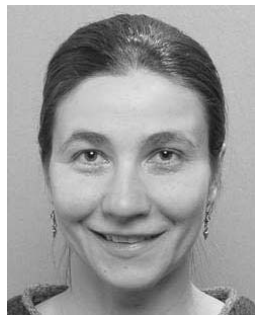

Madeleine Gibescu (M05) received the Dipl.Eng. in power engineering from the University Politehnica, Bucharest, Romania in 1993 and her MSEE and $\mathrm{Ph} . \mathrm{D}$. degrees from the University of Washington, Seattle,WA, U.S. in 1995 and 2003, respectively. She has worked as a Research Engineer for ClearSight Systems and as a Power Systems Engineer for the AREVA T\&D Corporation. She is currently an Assistant Professor in the Department of Electrical Sustainable Energy at the Delft University of Technology, The Netherlands.

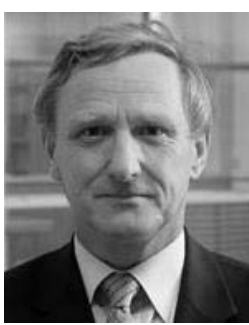

Wil L. Kling (M95) received the M.Sc. degree in electrical engineering from the Eindhoven University of Technology, the Netherlands, in 1978. From 1978 to 1983 he worked with Kema, from 1983 to 1998 with Sep and since then up till the end of 2008 he was with TenneT, the Dutch Transmission System Operator, as senior engineer for network planning and network strategy. Since 1993 he is a part-time Professor at the Delft University of Technology, and from December 2008 he is appointed as a full Professor and chair of Electrical Power Systems group at the Eindhoven University of Technology. He is leading research program on distributed generation, integration of wind power, network concepts and reliability issues. Prof. Kling is involved in scientific organisations such as Cigré and IEEE. He is the Dutch representative in Study Committee C6 Distribution Systems and Dispersed Generation and the Administrative Council of Cigré 